\title{
A hermenêutica em educação matemática: compreensões e possibilidades
}

\section{Hermeneutics in mathematics education: understandings and possibilities}

\author{
Fabiane Mondini \\ fabiane.mondini@gmail.com \\ Luciane Ferreira Mocrosky \\ mocrosky@gmail.com \\ Maria Aparecida Viggiani Bicudo \\ mariabicudo@gmail.com
}

\begin{abstract}
Resumo
Neste artigo apresentamos compreensões sobre a hermenêutica filosófica, apontando-a enquanto uma teoria universal, por ser abrangente, não particularizada, crítica e presente desde os primórdios da filosofia ocidental, quando mencionada em Aristóteles, por exemplo. Nossa intenção é tomar as discussões ocorridas no grupo de trabalho de filosofia, no V Seminário Internacional de Pesquisa em Educação Matemática e conduzir a discussão para um horizonte que abra clareiras, não colocando em julgamento linhas de trabalhos e, muito menos, arbitrando sobre "hermenêuticas" supostamente contrárias à fenomenologia heideggeriana e gadameriana. Assumimos assim, o compromisso de trazer novamente em debate "possibilidades" de se efetuar um trabalho hermenêutico, expondo compreensões que possibilitem aprofundar as discussões havidas, "des-velando" contribuições possíveis para a investigação e prática pedagógica em Educação Matemática.
\end{abstract}

Palavras-Chave: Educação matemática; Filosofia da educação matemática; Fenomenologia; Hermenêutica Filosófica.

\begin{abstract}
In this paper we presents insights into the philosophical hermeneutics, pointing it as a universal theory, be comprehensive, not individualized, critical and present since the dawn of western philosophy, when mentioned in Aristotle, for example. Our intention is to take the discussions that took place in the philosophy of working group in the "V Seminário Internacional de Pesquisa em Educação Matemática" and lead the discussion to a horizon that open glades, not putting on trial line work, much less, arbitrating on "hermeneutics" supposedly contrary to Heidegger, Gadamer's phenomenological. We thus commitment to bring again under discussion unveiling to make a hermeneutic work, exposing understandings that allow deepen the discussions, unveiling possible contributions to research and teaching practice in Mathematics Education.
\end{abstract}

Keywords: Education mathematics; Philosophy of mathematics Education; Phenomenology; Hermeneutics Philosophical.

\section{Introdução}

A construção deste texto foi iniciada em outubro 2012, ainda enquanto ocorriam as apresentações de trabalhos e os respectivos comentários no GT 11, Grupo de Trabalho "Filosofia da Educação Matemática”, do V SIPEM, Seminário Internacional de Pesquisa em Educação Matemática, realizada na cidade de Petrópolis-RJ. Durante o evento nos deparamos com um debate sobre 
hermenêutica e autores que sustentam modos de trabalhar hermeneuticamente. Um emaranhado de entendimentos foi sendo exposto, conduzindo o grupo de pesquisadores a uma encruzilhada com possibilidades de caminhos que conduziam à compreensão de hermenêutica pelas vias do trabalho de Heidegger, Gadamer, Ricoeur, Thompson. Tomando as exposições desses autores, foram sendo tramados desdobramentos sobre o que se entenderia por interpretar e compreender. Nesse debate, a interpretação exposta muitas vezes vinha seguida de adjetivos como, por exemplo, melhor, profunda.

Sabemos que uma discussão desse porte é abrangente e exige investigação aprofundada. Entretanto, neste artigo, nossa intenção é tomar as discussões no GT 11 mencionadas e conduzi-las para um horizonte que abra clareiras, não colocando em julgamento linhas de trabalhos e, muito menos, arbitrando sobre "hermenêuticas" supostamente contrárias à fenomenológica heideggeriana, gadameriana e a habermasiana e similares. Assumimos assim, o compromisso de trazer novamente em debate "possibilidades" de se efetuar um trabalho hermenêutico, expondo compreensões de modo a aprofundar os estudos no GT, "des-velando" contribuições possíveis para a investigação e prática pedagógica em Educação Matemática.

Lançada a semente nesse encontro, propomo-nos seguir o caminho já anunciado e apresentar os avanços de nossos estudos sobre a hermenêutica filosófica, apontando a hermenêutica enquanto uma teoria universal, abrangente, não particularizada, crítica e presente desde os primórdios da filosofia ocidental, quando mencionada em Aristóteles, por exemplo. Já de antemão, anunciamos que não temos por intenção assumir como válidos um método de interpretação e uma metodologia para a Educação Matemática. Trata-se de um texto que traz um estudo bibliográfico e introdutório sobre a Hermenêutica, pautada em uma perspectiva fenomenológica, com o objetivo de expor a compreensão enquanto um existencial humano e contribuir com as pesquisas em Educação Matemática que tematizam a compreensão: de professores, de estudantes, de textos, de conceitos, de sentido e de significado no âmbito dessa ciência.

\section{A Hermenêutica Compreendida da Perspectiva Fenomenológica}

Ao estudar significados de hermenêutica e sentidos trazidos na tradição filosófica do mundo ocidental, percebemos que ela pode ser explicitada por duas vias: como uma hermenêutica exegética, metódica e normativa, elaborada desde a antiguidade até o século XIX e, por meio da hermenêutica filosófica presente nos trabalhos de Martin Heidegger (1889 - 1976), Hans-Georg Gadamer (19002002) e Paul Ricœur (1913 - 2005), que expõem a hermenêutica como abertura mundana, portanto histórica, social e cultural, na qual o ato de compreender é entendido como constitutivo dos seres humanos, uma vez que ao existir compreende-se a si e a sua obra cultural. A teorização da hermenêutica enquanto método é definida como um modo de interpretar todos os textos, pautado em regras para legitimar a interpretação e a compreensão de modo explicito e nítido (PALMER, 2006, p. 46). Dentre os pesquisadores que trabalharam essa concepção destacamos Friedrich Daniel Ernst 
Schleiermacher (1768 - 1834) que descreve dois tipos de interpretações possíveis: a gramatical e a psicológica (ou técnica).

A primeira diz respeito à compreensão de uma expressão em sua relação com a linguagem, como uma parte desta, a segunda compreende um proferimento como uma parte do processo de vida do falante. A tarefa principal da interpretação psicológica é compreender como o autor pensa o significado do texto. Mas a compreensão não pode ser integralmente alcançada, porque a qualquer momento pode haver uma parte que não compreendemos propriamente. A má compreensão é primordial e não pode ser claramente ausentada em definitivo. (NEGRU, 2007, p. 53).

Wilhelm Dilthey (1833 - 1911) dá continuidade aos trabalhos de Schleiermacher e define a compreensão como a manifestação da experiência vivenciada (Erlebnis). Para ele Erlebnis "é aquilo que na cadeia do tempo forma uma unidade no presente porque tem um significado unitário, é a mais pequena entidade a que podemos chamar experiência" e experiência é cada unidade das partes da vida ligadas por um sentido comum - mesmo quando as várias partes se separam uma das outras por eventos que as interrompem" (PALMER, 2006, p. 113-114). Ao relacionar experiência de vida com fatores internos contextualizados historicamente e explicitados nas expressões humanas, o termo "compreensão" passa a significar o "princípio da existência humana histórica abrindo caminho para as discussões a respeito das condições ontológicas que tornam a compreensão possível (NEGRU, 2007, p. 54)", que mais tarde fundamentam os trabalhos de Heidegger sobre a hermenêutica fenomenológica. Para a hermenêutica fenomenológica, a compreensão é um existencial, o que significa que é uma estrutura

a priori que revela o modo como o Dasein existe. Como existencial, a compreensão opera projetando anteriormente ao Dasein as suas possibilidades. Essas projeções são organizadas pela interpretação, que tem o papel de tornar explícito o que nós, enquanto seres humanos, já somos simplesmente porque existimos. Por trás de toda interpretação está a estrutura prévia da compreensão; toda interpretação é baseada em algo que temos previamente - ter prévio (Vorhabe), em algo que vemos previamente - ver prévio (Vorsicht) e em algo que apreendemos antecipadamente concepção prévia (Vorgriff) (NEGRU, 2007, p. 54).

A compreensão fenomenológica não é previamente fixada, mas é historicamente constituída pela experiência vivenciada pela pessoa que sempre já é junto ao mundo em que outros também são e, desse modo, torna-se uma hermenêutica da existência humana. Portanto "a fenomenologia do Dasein é hermenêutica, no sentido original da palavra, ou seja, é um trabalho de interpretação" (PALMER, 2006, p. 134). Portanto, interpretação do que aí está. Com Heidegger a hermenêutica, enquanto interpretação, define-se numa "ontologia da compreensão e da interpretação", agora uma compreensão ontologicamente constituída, ou seja,

é o poder de captar as possibilidades que cada um tem de ser, no contexto do mundo vital em que cada um de nós existe. Não é capacidade ou o dom especial de sentirmos a situação de outra pessoa, nem é o poder de captar mais profundamente o significado de alguma manifestação da vida. A compreensão não se concebe como algo que se possua, mas como um modo ou elemento do ser-no-mundo. A 
compreensão é a base de toda a interpretação, é contemporânea de nossa existência e está presente em todo ato de interpretação. (PALMER, 2006, p.136).

Com os trabalhos de Heidegger sobre a compreensão humana, a hermenêutica tornase um modo do ser humano ser no mundo, suplantando a definição de hermenêutica como um método de interpretação. Essa mudança de concepção é o ponto de partida dos trabalhos de Gadamer sobre a hermenêutica fenomenológica.

Em seu livro Verdade e Método, Gadamer explicita que o método não é o caminho para a verdade e, portanto, a hermenêutica filosófica não está estruturada como um método ou uma metodologia da compreensão. No entanto, a hermenêutica fenomenológica não nega a importância do método e da metodologia, enquanto rigor de investigação. Porém, nunca dada a priori ao modo de um caminhar passo a passo previamente definido.

A questão fundamental apresentada por Gadamer pode ser assim formulada: "como é possível a compreensão da experiência humana no mundo?" A resposta que ele elabora para essa questão abrange interpretações históricas, mas não se limita a elas já que "designa também o movimento básico da existência humana, construído pela finitude e historicidade, abrangendo a globalidade da experiência no mundo e, por esse motivo, podemos afirmar que o movimento da compreensão é universal" (PALMER, 2006, p. 169). Essa concepção de universalidade da hermenêutica fenomenológica traz implicações metodológicas em que a verdade não é alcançada metodicamente, mas estruturada dialeticamente.

\begin{abstract}
Rigorosamente falando, o método é incapaz de revelar uma nova verdade; apenas explica o tipo de verdade já implícita no método. A própria descoberta do método não se alcançou metodicamente, mas sim dialeticamente, isto é, como resposta problematizante ao tema investigado. No método o tema a investigar orienta, controla e manipula; na dialética, é o tema que levanta as questões a que irá responder. A resposta só pode ser dada se pertencer ao tema e situado nele. A situação interpretativa não é mais a de uma pessoa que interroga e a de um objeto, devendo aquele que interroga construir 'métodos' que lhe tornem acessível o objeto [...] (GADAMER 1999, p. 170).
\end{abstract}

Nesse sentido, Gadamer traz a compreensão como uma tradição e a comunicação como uma fusão de horizontes. A compreensão é entendida como um movimento dialético caracterizado pela concordância, ou seja, o encontro do nosso presente com nossa experiência histórica que se abre ao mundo como um "milagre da compreensão", no sentido de que o compreendido é constatado num dado momento em que o foco incide no que é percebido com clareza, perdendo-se no tempo e no espaço o movimento vivenciado e vivo da compreensão. O sentimento de que as coisas não se dão prontas, mas de repente acontecem como se fosse operado um milagre em que a compreensão brotasse de algo plantado em uma simbiose dentro-fora de cada um, individualmente e de todos presentes na história culturalmente dada no mundano.

Para o autor esse milagre não é uma 'comunhão misteriosa' entre o intérprete e o autor de um texto, como se o interprete pudesse compreender as intenções do autor ao escrever num simples 
acordar. O milagre da compreensão está no sentido comum entre o que é trazido pela tradição do texto e o intérprete, é um encontro: é a fusão de horizontes. Esse movimento não é nem subjetivo e nem objetivo, mas intersubjetivo, de modo que a compreensão vai se fazendo. Assim sendo, Gadamer (1999) afirma: "Onde uma tradição nos alcança, torna-se presente toda uma humanidade passada, que se faz conhecer" (GADAMER 1999, p.438).

A distância temporal entre nós e o que é trazido pela tradição não é algo que precise ser superado. "É uma possibilidade positiva e produtiva do compreender. Não é um abismo devorador, mas está preenchido pela continuidade da herança histórica e da tradição, a cuja luz nos é mostrado todo o transmitido" (GADAMER, 1999, p.445).

Também "não é um compreender melhor, nem saber mais, no sentido objetivo, em virtude de conceitos mais claros [...] é simplesmente compreender". (GADAMER, 1999, p. 444). A compreensão é abertura, já que para compreender é preciso estar disposto para tal. A hermenêutica, nesse sentido, não traz consigo a certeza de uma metodologia, mas a possibilidade de experienciar em comunidade, de maneira universal.

A universalidade da Hermenêutica de Gadammer é destacada por Negru (2007). Segundo ele, para compreender a universalidade da hermenêutica fenomenológica é preciso compreender os escritos de Gadamer em duas perspectivas complementares e não excludentes: da dimensão linguística da compreensão e da compreensão humana do mundo em geral.

No primeiro caso, a universalidade vem do fato de que, a compreensão é linguística e apresenta-se em qualquer momento em que temos um contato com a tradição. No segundo caso, a universalidade vem do fato de que o ser humano é um ser-nomundolinguisticamente, o que quer dizer que a partir da linguagem temos a experiência do mundo. [...] Em ambos os casos, a universalidade da hermenêutica é dada pela universalidade da linguagem, a qual, de acordo com Gadamer (1988, p. 433), torna a hermenêutica "uma filosofia universal e não apenas a uma base metodológica das assim chamadas ciências humanas" (NEGRU, 2007, p. 56).

A dimensão linguística da universalidade da hermenêutica fenomenológica gadameriana é contestada no trabalho de Jürgen Habermas (nascido em 1929). Segundo ele, Gadamer não considera o fato de que,

\footnotetext{
por um lado, a linguagem é um meio de dominação e de poder social e, por outro, a linguagem é afetada por fatores subconscientes, os quais têm como efeito a sua distorção sistemática. No primeiro caso, em vez de hermenêutica deveríamos falar de uma crítica de ideologias, no segundo, temos que substituir a hermenêutica por uma hermenêutica de profundidade (depth-hermeneutics), a qual pode compreender corretamente como a linguagem pode ser distorcida pela psicopatologia. (NEGRU, 2007, p. 56).
}

Porém na comunicação não patológica também pode ocorrer a distorção "da expressão do que é ininteligível de acordo com as regras da comunicação pública, e que permanece inacessível até mesmo para o próprio falante". (NEGRU, 2007, p. 56). Nesse aspecto, Habermas afirma que a hermenêutica filosófica não abre espaço para a crítica e a reflexibilidade e não considera as distorções que podem acontecer na linguagem. Assim como existe a psicanálise para a compreensão das neuroses 
manifestadas pela linguagem, a hermenêutica de profundidade mencionada por Habermas é um modelo que investiga as distorções da comunicação. "Ao teorizar a comunicação sistematicamente distorcida, que implica a hermenêutica de profundidade, Habermas colocou em questão a autoconcepção ontológica da hermenêutica, que Gadamer explica seguindo Heidegger" (NEGRU, 2007, p. 58).

Para Habermas o procedimento executado por Gadamer gera uma absolutização da hermenêutica, ou seja, é limitada pelo "eu" que interpreta e compreende, fechando-se no círculo existencial hermenêutico, sem abrir ao sujeito a possibilidade de transcender em sua compreensão. É curioso que Habermas se refira ao "círculo existencial hermenêutico" como se fechando em si, evidenciando seu não entendimento de que esse círculo diz de abertura de horizonte de compreensão, pois, como presente em Heidegger e Gadamer, esse horizonte não tem uma linha que o limite, porém a cada avanço, ele se distancia. Ao mesmo tempo em que esse autor critica a hermenêutica filosófica, aponta a linguagem como uma "metainstituição, da qual dependem todas as instituições sociais, uma vez que a ação social só se constitui na comunicação da linguagem corrente (BICUDO, 1993, p. 73)". Por outro lado, segundo Bicudo (1991), a linguagem também é dependente dos processos sociais e é um meio de dominação e de poder, ideológica e institucionalizada. "A experiência hermenêutica que, na visão de Habermas, se depara com essa dependência do contexto simbólico, com referência às relações fáticas, passa a ser crítica da ideologia" (BICUDO, 1993, p. 73).

Gadamer responde a crítica feita a seu trabalho afirmando que a hermenêutica tem por objetivo compreender tudo o que é possível de ser compreendido, é abertura e não um limitador como afirmado por Habermas. A compreensão e a interpretação são existenciais ao homem, é um modo de ser do homem que já é sempre no mundo, que compreende e compreende-se a partir do seu mundo circundante. A Hermenêutica Filosófica é fundamentada nos textos de Heidegger, e, portanto, a compreensão "não é apenas um processo mental, que se manifesta de modos conscientes e inconscientes, mas é ontológica, ou seja, é temporal, intencional e histórica (PALMER, 2006, p, 145).

O debate que ocorre entre Gadamer e Habermas é sustentado pelo fato de que na teoria habermasiana nem tudo é interpretação (Verstehen). (BATISTA, 2012, p.113). Segundo essa autora, para Habermas existe a explicação (Erklären) que complementa a interpretação. Para Habermas a organização social regulamenta e controla os indivíduos. "o sistema econômico, por exemplo, cuja forma de regulação é o dinheiro. Ou o sistema político, que tem no poder seu meio de controle, enquanto que o Estado se vale da burocracia (HABERMAS, 1989; 1981 apud BATISTA, 2012, p.114). Nesse contexto a fala do sujeito é "regulada" e como o individuo está sujeito à dominação é necessário uma hermenêutica de profundidade, como advogada por Habermas, para analisar as questões ideológicas presentes. Nesse sentido, "Habermas postula a necessidade de uma 'teoria crítica da sociedade como um complemento à hermenêutica gadameriana'. Gadamer responde as críticas afirmando que o problema está no modo como Habermas compreende a Hermenêutica, como um 
'método' que pode ser 'útil' para as ciências sociais" (BATISTA, 2012, p.113), e não como uma experiência humana. Para Gadamer a compreensão não é um fazer subjetivo do homem e a hermenêutica não tem por objetivo "validar" uma compreensão. Seu objetivo "é conceber a compreensão de um modo tão lato quanto possível" (ESPÓSITO, 1991, p.103). Assim, não faz sentido transformar a hermenêutica enquanto uma filosofia, em um conjunto de regras ou passos para validar uma interpretação subjetiva, pois ela é além disso.

É o movimento básico da existência humana constituída pela sua finitude e historicidade, por conseguinte abrange a globalidade da experiência humana no mundo. Por isso a afirmação de que o movimento da compreensão é englobante e universal (GADAMER 1999, prefácio).

Nesse sentido, o conhecimento é algo que nos constitui e não algo que possuímos. A hermenêutica permite avançar os limites positivistas da ciência moderna aproximando-a da dialética socrática. Ao opor a 'Verdade' ao 'Método' e ao afirmar que a verdade se constitui para o sujeito dialeticamente e não é alcançada metodicamente, Gadamer faz uma crítica ao modo de fazer ciência estruturada nas interpretações metódicas que impedem a revelação de novas verdades. Enquanto em um movimento dialético, tal como ocorre na hermenêutica filosófica, há a possibilidade de abertura, não somente para o conhecimento, mas para a experiência do sujeito inserido no contexto da tradição, em outras palavras, "para a sabedoria" (ESPÓSITO, 1991, p.104).

Com este texto não queremos prescrever um estilo de hermenêutica, mas sim esclarecer que os autores que seguem a filosofia de Habermas reproduzem muitas de suas críticas quando se referem ao conceito de "círculo existencial hermenêutico", ainda que não o citem especificamente. Também afirmam que vão além da análise existencial hermenêutica na medida em que não se fecham no "eu", como se fosse possível um mundo humano, mundanamente vivido, sem o "eu" e, também um "eu" sem esse mundo. Além disso, seguem um método em busca de uma verdade pré-dada pelo método, embora neguem sua existência. Prestados os esclarecimentos que sustentam a universalidade da hermenêutica fenomenológica passaremos agora a apresentá-la como uma metodologia de pesquisa no âmbito da Educação Matemática.

\section{A Hermenêutica Fenomenológica nas Pesquisas em Educação Matemática}

Pesquisar em Educação Matemática "não é pesquisar nem em Matemática nem em Educação", como nos disse Bicudo (1993, p.2), apesar de haver interseções entre Educação Matemática e Educação e entre Educação Matemática e Matemática. As pesquisas que se dizem pertencer à Educação Matemática se preocupam com o fazer Matemática, com o compreender a Matemática, com o interpretar a Matemática, com os significados históricos sociais e culturais da Matemática, com as ações politicas e pedagógicas que organizam a Matemática no contexto escolar. (BICUDO, 1993, p.1 2).

O movimento de pesquisar em Educação Matemática abrange 
a subjetividade do pesquisador, que traz consigo seu horizonte de compreensão; a estrutura do texto, que fornece indicadores da sua lógica, que revela o discurso do autor, ou seja, sua compreensão do investigado, do que para ele faz sentido e está escrito no texto apresentado para debate; os aspectos históricos do mundo da obra de que o texto fala; e a meta-compreensão do fazer pesquisa , (BICUDO e PAULO, 2011, p. 16).

Ao inquerir o campo da Educação Matemática busca-se por novos sentidos, por outras interpretações e compreensões, produzindo conhecimento num processo contínuo de compreensãointerpretação-compreensão. Nessa perspectiva é que a hermenêutica se apresenta como uma possibilidade rigorosa para a pesquisa, ao trabalhar com a linguagem como horizonte de uma ontologia.

A hermenêutica é definida por Gadamer (1999, p. 594 - 595) como "o entrelaçamento entre o acontecer e o compreender". Esse acontecer não é um "extrair" por meio de procedimentos metodológicos "o que realmente se quis dizer e tal como realmente era, no momento em que foi dito". Esse procedimento, por vezes comum em pesquisas no âmbito da Educação Matemática, é ingênuo, visto que o sentido pelo autor, só a ele pertence. O acontecer das pesquisas em Educação Matemática está na compreensão do que se torna possível por meio da linguagem "que chega até nós como tradição e que devemos ouvir nos atingir, como se fosse dirigida a nós e se referisse a nós mesmos". (GADAMER 1999, p. 594 - 595). Aquele que compreende já está incluído no acontecimento do compreender, em virtude de "ver" o sentido do que está sendo investigado.

Ao falarmos em compreensão da perspectiva da fenomenologia, não nos referimos "a expressão das realidades internas", como proposto por Dilthey, ou a um método que se fundamente na consciência humana, ou ainda, a algo pautado nas categorias da consciência, mas sim, ao

poder de captar as possibilidades que cada um tem de ser no contexto de que cada um de nós existe; a compreensão não é algo que se possua, mas um modo de ser-nomundo. É ontologicamente fundamental e anterior a qualquer ato da existência (ESPÓSITO, 1991, p.99).

É nesse sentido que Heidegger afirma em "Ser e Tempo" (2012) que o ser humano é um hermeneuta ao elaborar continuamente possibilidades de investigação. Hermenêutica, quando compreendida nesse sentido, torna-se sinônimo de "analítica da existencialidade da existência" (ESPÓSITO, 1991, p.99).

Trata-se de uma hermenêutica que elabora ontologicamente a historicidade da "presença" como condição ôntica de possibilidades da história fatual, isto é, a hermenêutica enquanto metodológica da interpretação dos estudos humanísticos, é uma forma derivada que se assenta na função ontológica primária da interpretação e a partir dela se desenvolve. [...] A hermenêutica transforma-se numa ontologia da compreensão e da interpretação (ESPÓSITO, 1991, p.99).

Pesquisando-se no âmbito da Educação Matemática também interpretamos compreendendo e compreendemos interpretando o que é expresso pela linguagem matemática. Linguagem essa tomada como "discurso pronunciado" (ESPÓSITO, 1991, p.99), ou seja, o ouvir, o falar e o pronunciar a Matemática. A hermenêutica é sempre um fazer de forma circular, pois o 
homem-ser se dá na linguagem, enquanto na linguagem acontece um pronunciar da mensagem que o ser endereça ao homem. [...] O homem está a serviço do ser, anunciando-o, respondendo assim a solicitação que lhe é feita. [...] A relação ser e homem parte do des-velamento do ser que ao se tornar presente diz-se e endereça-se ao homem e este ao captar coloca-se a serviço da mensagem do ser.

Desse modo, não há como assegurar uma compreensão total e livre de preconceitos, o que nos mostra o limite do "método" científico, mas não da Ciência. Por outro lado, se não pode haver uma interpretação livre de pressupostos; não há método que estabeleça uma "interpretação correta". Qualquer tentativa de elaborar um método interpretativo cai na impossibilidade da compreensão. E é nessa perspectiva que destacamos a Hermenêutica como uma possibilidade para as pesquisas em Educação Matemática, enquanto um modo de compreender o fenômeno da linguagem, com suas diferentes manifestações e expressões culturais.

\section{Retomando o Exposto ao Modo de Uma Síntese (In)Conclusiva}

Neste artigo apresentamos uma discussão sobre Hermenêutica, enquanto uma Filosofia que vem atender a crescente demanda das pesquisas em Ciências Humanas, inclusive aquelas em Educação Matemática, sobre a compreensão. Entendemos a Hermenêutica como "abertura" e, enquanto abertura "intenta desvincular a Educação [Matemática] das amarras conceituais provenientes da visão científico-objetivista" (ALVES, 2011, p.1).

Um dos aspectos discutidos nesse texto diz da compreensão, enquanto impossibilidade de esgotar um conceito em sua totalidade ou expor uma autorreflexão e, nesse sentido, apresentamos a Hermenêutica "como uma forma de racionalidade" (STEIN, 2008), portanto uma forma de saber.

Ao construir etapas de análise hermenêutica cria-se um método e, portanto, limita-se às possibilidades de abertura de horizonte do leitor frente ao texto. Para a compreensão de um texto é necessário uma organização dialética e dialógica, que possibilite o encontro de horizontes entre o texto e o autor e produza uma compreensão, subjetivamente percebida e compreendida enquanto compreensão prévia e historicamente constituída. Por outro lado, ao produzir saber há a produção de uma racionalidade. E,

cada racionalidade sugere abordagens alternativas para as questões que sempre desafiaram a inteligência humana. A racionalidade ocidental é um esforço grandioso para determinar a ordem dos fenômenos naturais e humanos e definir suas leis e relações. [...] A hermenêutica é uma racionalidade decorrente da exigência de se contrapor a uma época que procurou conhecer seguindo apenas a racionalidade de procedimentos empírico-formais e da explicação causal, própria das ciências naturais. (ALVES, 2011, p.1).

A Hermenêutica Filosófica questiona a verdade pautada apenas nos métodos positivistas e estrutura uma racionalidade constituída na historicidade e na tradição. Historicamente, a hermenêutica já foi sinônimo de interpretação e de tradução. Concomitante ao positivismo científico, que estrutura a verdade em dados objetivos, ela se torna um caminho para verdade, indo além do método científico, tornando-se um meio de filosofar, cultural e historicamente situado. Para Heidegger, a verdade "é 
temporal, situa-se na historicidade, tornando-se condição de possibilidade" (STEIN, 2001, p. 104). Com Gadamer, há a "superação da filosofia da subjetividade, vinculando o sujeito que compreende à historicidade, $[\ldots]$ o abandono da ideia de objetividade e do fundamento cartesiano da ciência, para deixar revelar a verdade na linguagem" (ALVES, 2011, p.21).

Quando impera uma racionalidade positivista no modo de fazer pesquisas, como vem acontecendo no âmbito da Educação Matemática, o conhecimento passa a ser algo construído por meio de técnicas que validam a verdade. Quando nos valemos dos procedimentos hermenêuticos, já não temos mais apenas um caminho a seguir. Nesse sentido, trazemos a Hermenêutica Filosófica como uma possibilidade de abertura a esse campo do conhecimento.

\section{Referências}

ALVES, M. A. Da hermenêutica filosófica à hermenêutica da educação. In: Acta Scientarium Education, Maringá, v. 33, n.1, 2011, p. 17-28. Disponível em: http://.periodicos.uem.br\% 2Fojs\%2Findex.php\%2FActaSciEduc. Acesso em: 22/09/2014.

BATISTA, M. Hermenêutica Filosófica e o debate Gadamer-Habermas. In: Revista de cultura política. v.2, n.1. Disponível em: http://www.seer.ufu.br/php/criticasociedade/article/ view/15000. Acessado em: 24 de jan. 2014

BICUDO, M. A. V. A Hermenêutica e o Trabalho do professor de Matemática. Cadernos da Sociedade de Estudos e Pesquisas Qualitativos. v.3, n. 3 (1993). São Paulo, p. 63-96

BICUDO, M. A. V. Realidade virtual: uma abordagem filosófica. Ciências humanas e sociais em revista, v. 33, p. 114-127, 2011.

BICUDO, M. A. V; PAULO, R. M. Um exercício filosófico sobre a pesquisa em educação matemática no Brasil. Bolema, Rio Claro, v.25, n. 41 p. 251-298, 2011.

ESPÓSITO, V. H. C. Hermenêutica: estudo introdutório e o Trabalho do professor de Matemática. Cadernos da Sociedade de Estudos e Pesquisas Qualitativos. v.2, n. 2 (1991). São Paulo, p. 85-112

GADAMER, H. G. Verdade e método - Traços fundamentais de uma hermenêutica filosófica. Tradução de. Flávio Paulo Meurer. Petrópolis: Vozes, 1999. 731 p.

HEIDEGGER, M. Ser e Tempo. Tradução de Fausto Castilho. Campinas: Ed Unicamp. Petrópolis: Vozes, 2012.

NEGRU, T., "O debate entre Gadamer e Habermas e a Universalidade da Hermenêutica". Disponível em: www.academia.edu/406539/negru-T. o_debate_entre_gadamer_e_habermas_e_a_ universalidade_da_hermen\%C3\% AAutica. Acessado em jul de 2014.

PALMER, Richard E. Hermenêutica. Lisboa: Edições 70, 2006. Tradução de: Maria Luísa Ribeiro Ferreira.

STEIN, E.. Aproximações sobre hermenêutica. 2a ed. Porto Alegre: EDIPUCRS, 2008. 